\title{
IJM CR
}

International Journal of Medical and Clinical Research

ISSN: 0976-5530 \& E-ISSN: 0976-5549, Volume 2, Issue 2, 2011, pp-67-71

Available online at http://www.bioinfo.in/contents.php?id=39

\section{CHALLENGES IN CADAVER AVAILABILITY FOR LEARNING AND RESEARCH IN MEDICAL SCIENCES}

\author{
SINGH A.K. ${ }^{1}$, SHARMA R.C. ${ }^{2}$, SHARMA R.K. ${ }^{3}$, MUSMADE D.M. ${ }^{4}$ \\ 1Department of Anatomy, Government Medical College Haldwani, Nainital, Uttarakhand \\ 2Professor \& Head of Physiology, Government Medical College Haldwani, Nainital, Uttarakhand \\ 3Professor \& Head of Obstetrics and Gynecology, MGM Medical College, Kamothe, Navi Mumbai \\ ${ }^{4}$ Department of Physiology, DY Patil Medical College Navi Mumbai \\ *Corresponding author. E-mail: drsharmax@gmail.com
}

Received: October 06, 2011; Accepted: November 02, 2011

\begin{abstract}
Use of unclaimed or donated bodies for education \& research in anatomical sciences have been recognized as valuable means of cadaver by the Anatomical professionals but adequate and continuous availability of cadaver has been one of the major concerns of the stakeholders of health science institutions and biomedical research organisations in order to fulfil objectives of anatomy curriculum of the graduate, postgraduate and specialist training \& research programmes in medical sciences. Deficiency of cadaver for dissection and research in medical institutions has been further deteriorated in present scenario attributed to steep increase in number of medical, dental and other health science institutions during last decade. The present paper analysed the existing sources of cadavers associated with challenges in process of procurement by the medical colleges and other health science institutions to identify the issues needs to be addressed immediately in order to ensure sustained solutions of these challenges and augment adequate cadavers supply to meet rapid rate of advancement in surgical techniques, altered pattern of structural shape, size and histology. An attempt has also been made to suggest possible sustainable solution for promoting voluntary whole body donation as well as corrective measures for optimum utilisation of unclaimed body in acceptable form from government sources for learning \& research in anatomical sciences.
\end{abstract}

Keywords- Anatomy Act, Unclaimed Body, Body donation, Anatomy Learning,

\section{INTRODUCTION:}

In almost all the health sciences courses, study of anatomy serves as the foundation for understanding the medicine, which is achieved only through the dissection of cadaver. The cadavers, beside being used for teaching medical and other health sciences courses, are also used for research by the medical professionals for the development of new surgical procedures, advance operative techniques \& therapeutic advancement in medical science and perform special anatomical studies. The common obstacles encountered by the health sciences institutions for procurement of cadavers from existing sources are of diverse nature such as legal, constitutional, cultural, religious, sociological, economical, procedural, administrative and educational [1-3]. Use of various body parts of after death for a wide variety of purposes like transplantation, isolating and extracting hormones, skeletal structures, research, instructing medical personnel has multiplied the shortage of cadaver supply to medical institutions for dissection \& research. Attempts have been made to develop computerized imaging models in anatomy as an valuable option and introduced in as learning tool for teaching anatomy, but it could not replaced cadaver dissection, based on the fact that cadavers provide a wider range of perceptions, both haptic (hardness, size, shape, borders) and visual (depth, texture, relations). Hence it is maintained that cadaveric studies is a valuable tool for education \& research in medical sciences.

The main sources of cadaver procurement for the medical colleges depends on (1) availability of unclaimed deceased persons whose burial had to be carried out at the expense of the state or the municipality or refusal to claim the body by the relatives and (2) voluntary donations by relatives of the deceased or common peoples of any community according to the dead person's wishes. But there are various factors such as extensive burns, mutilation, advanced decomposition, or a history of contagious diseases (i.e. hepatitis $B \& C$, AIDS, active tuberculosis, syphilis, etc.), suicide or homicide, removal of organs (except for eyes) etc render the body unacceptable for an anatomical donation, thus creates the major setback to procurement of cadavers to medical institutions for education and research. It is therefore the suitability of donated or unclaimed body for dissection or research play very important factor for deficient supply of cadavers, usually faced by the medical colleges. 
Present paper is an attempt to carry out situation analysis of existing sources of cadavers and associated challenges leading to shortage of cadaveric supply to health science institutions mainly by medical colleges in order to identify the issues such as limitations in procedure and suitability of unclaimed cadavers from government sources, social and administrative challenges in body donation such as age, social, cultural, personal characteristics, attitude of donor and donor's relatives, and lack of communications between donor and cadaver recipient, importance of body donation etc, to provide sustainable solutions for cadaver procurement to meet the needs of the health science institutions \& medical professionals for anatomy learning and research in medical sciences.

\section{UNCLAIMED CADAVERS;-SUITABILITY \& AVAILABILITY}

It is estimated that approximately two-thirds of human bodies are used for educational purposes, and one-third for research ${ }^{4}$. The cadavers used by medical students and research mainly to study the normal structure of the whole human body, hence all unclaimed or donated bodies are not usually not serve the objectives of the curriculum. The Anatomy act regulates the use of dead bodies for medical purposes provides for the supply of unclaimed bodies to the hospitals and teaching institutions for the purpose of anatomical examination and dissection and other similar processes [5]. The unclaimed bodies are the bodies of individuals, who have died in a hospital or nursing home, remain unclaimed by family, homeless or indigent people found on the street. These unclaimed bodies are however are rarely used these days inspite of ease of availability in government mortuaries as they are not found suitable for anatomical study [6]. Different factors that may render the unclaimed body unacceptable for an anatomical use being subjected to postmortem, infective disease, distorted normal organ structures due to chronic illness, prolonged \& poor storage and preservation of body after death.

Acquiring adequate numbers of bodies for dissection had been a challenge for most of the medical institutions since as early as in $18^{\text {th }} \& 19^{\text {th }}$ Century and had to often resorted to robbing graves but in the 20th century, American society adopted the legislation regulating release of the unclaimed bodies of individuals dying in public institutions to medical schools for dissection, thereby effectively ending grave robbery. After introduction of Uniform Anatomical Gift Act, drafted by the National Conference of Commissioners on Uniform State Laws in the USA drastically reduced the shortage of bodies and organs in medicine, and served as a legislation template worldwide. The rationale behind the use of unclaimed bodies was to reduce the state's resources on account of disposal of unclaimed bodies. Hence instead of burying them, the cadavers are passed on to medical schools by the Government for dissection, thus benefitted both the state and the medical school. It is reported [7] that unclaimed bodies sourced from government mortuaries provided $77.8 \%$ of all bodies used for dissection between 1956 and 1996. Almost all of the black and coloured (mixed heritage) bodies were received from government mortuaries $(99 \%$ and $95.8 \%$, respectively), whereas only $34.1 \%$ of the white bodies were unclaimed bodies. The practice continues across Africa today [8]. In one of the Nigerian medical school all the cadavers were supplied from the state hospital as unclaimed bodies (presumably of homeless people), accident victims, or suspected bandits shot by police [9]. The situation is similar in Bangladesh [10], Brazil[11] and India [12]. In United States and Canadian medical schools, $20 \%$ of total cadavers are still unclaimed bodies, while in some state such as Maryland, Pennsylvania, North Carolina, Michigan, and Texas, the state anatomy board provide unclaimed bodies automatically[13,14]. In some other states availability of unclaimed bodies is adequate on account of accumulation dead bodies in state mortuaries attributed to inability of relatives and family members to afford funerals expenses and poor funding by government for public burials[15]. In contrast, medical schools in Kansas and Oregon have recently decided to refuse to accept unclaimed bodies despite their legality[16].

The present scenario reveals that procurement of unclaimed cadavers from government resources may be a easily accessible means for cadavers supply for learning and research but whether it ensure the quality of cadaver in terms of suitability i.e. study of normal structure, remains a moot question. There is no data available indicating the percentage of suitable \& normal body available for dissection or research in these institutions, even though there is adequate cadavers supply to medical school[17]. It is pertinent to mentioned that adequate availability of unclaimed body form the government mortuaries are not as important as their usefulness \& suitability to provide normal human structure to health sciences students in order to provide strong foundation of medicine. At this point, it is important to consider whether we should resort to use of unclaimed bodies form government resources or ensure quality of source of cadavers, owing a strong responsibility to educate members of our local government mortuaries to show them methods of preservation, storage, earliest transport of unclaimed body to medical schools [18], optimization of infrastructural \& administrative measures to maintain normal structure of body after death and respectful burial of remnants of dissected bodies as an obligations to relatives of unclaimed cadavers in order to experience the perception that body of their loved ones has been used for welfare of the mankind with respect and thus, in the long-run, will have positive spin-offs for both medical school and their society.

Considering the above facts of the present situation, it established that acquisition of unclaimed cadavers is a temporary solution to the challenges of shortage of cadavers for dissection by the medical students to learn human gross anatomy or for research by postgraduates until there is great deal of infrastructural, administrative and social reforms are introduced in government 
mortuaries to achieve optimization in methods of preservation, storage, earliest transport of unclaimed body to medical schools, infrastructural \& administrative facilities to maintain normal structure of unclaimed body after death. Further, the legal provisions regulating the preservation and storage of unclaimed bodies and envisaging the postmortem of bodies irrespective of cause of death needs to be addressed to avoid the unwarranted removal of normal organs of unclaimed bodies.

\section{BODY DONATION; SUPPLEMENT OR COMPLIMENT?}

Many countries have understood that cadaver shortage can only be addressed with establishing bequest program centers, which are contributing effectively to cause shift in awareness and attitudes toward organ and body donations[19, 20, 21]. The term body donation[22] is defined as one passes away, the family members bequeath one's body for medical education and research purposes without any compensation in any form for doing so with a motto of preserving public health". People donates their bodies to achieve their own postmortal desires, or to contribute to the education but some donors were willing for their bodies to be plastinated to achieve physical immortality irrevocably changing the term donation[23]. However number of persons who decide whole-body donation for the purposes of medical science is extremely remains low. It is reported that demographic and attitudinal factors are strongly related to willingness to consider whole body donation and suggested that there is a need to initiate efforts by health professionals to enhance donation after addressing the ways such as, younger age, race/ethnicity, less education and income, greater number of dependents, marital status, and attitudes about religion/spirituality, trust in hospitals, and income, gender, and racial/ethnic discrimination in hospitals,etc which are potential factors facilitator or barriers to donation[24].

There are different factors believed to play a role towards body donation. The most frequent reasons for making a body bequest were to aid medical science and gratitude to the medical profession as reported by Fennell and Jones $^{25}$. It has been showed that demographic and attitudinal factors were found to be strongly correlated to willingness to consider whole body donation[26]. In another study Chung and Lehman[27] concluded that the existing consent procedures for cadaver donations at United States medical schools did not provide sufficient information to the potential donors to constitute a fully informed consent. It was mentioned in another study by Boulware et al. that demographic, cultural, attitudinal and clinical associated with willingness to donate cadaveric and living related organs affect the general public's willingness to donate organs, but their relative contribution is different for living related versus cadaveric donation[28]. Golchet et al. also reported in his study that many factors such as age, religion, culture, personality characteristics, and views on death and mortality, body image and humanitarian concerns influence people's opinion towards body donation[29]. A cross sectional study amongst medical professionals in the age group of 25-65 years was conducted in India, demonstrated that the $8 \%$ of the medical professionals were unaware of the term body donation and $85 \%$ believed that donated bodies were misused. A large proportion of the respondents did not know about the authority that oversaw body donation, or its criteria for accepting donated bodies and diseases for which bodies were screened before acceptance. Only $22 \%$ of polled physicians were willing to donate their bodies for medical education, but $68 \%$ expected the public to do the same. It has been argued that the professional and social environments two main constraints in promoting whole body for research and anatomy learning. These observations suggest emphasis on the common people of the society about the selfless act of body donation besides educating medical students[30]. In contrast to above, Netherlands has witnessed a steep increase in the number of bodies donated for medical research and training. It is reported that only $(25 \%)$ of the donors were health care professionals and $11 \%$ involved in education. Further it is only $8 \%$ of respondents prompted to donate their bodies without money motives inspite of poor economic constraints ${ }^{9}$. The analysis of the all the ten factors reveals three principal dimensions for motivations for body donation: (1) a desire to be useful after death, (2) a negative attitude towards funerals and (3) expression of gratitude[31].

The controversy over ethics, poor availability and effectiveness of using cadavers as learning tool has been the subject of discussion for past few years. Comparative studies have indicated that students learn anatomy well by studying prosections as they do by traditional dissecting[18, 32] while other reported modest advantage for students performing traditional dissection over studying prosections as a means to learn anatomy but cautioned that learning on cadavers may have negative consequences for students, which may outweigh the benefits of using a human body as a learning tool[33]. Moreover, the use of cadavers for dissection has been identified by some as expensive, time consuming and potentially hazardous[34]. It is for these reasons that dissection as a learning modality has been marginalised from medical curricula to the despair of some academics and some universities have embraced other learning modalities such as problembased learning (PBL) developed at McMaster University[35].

Another issue in solving the problem with body procurement is its perplexed relationship with transplantation. It is worth noting that acquiring small samples of human tissue has a much lesser reaction in the socio-cultural environment, in comparison to organ and whole-body procurement[36]. From the moral point of view, harvesting viable tissues and organs has an undeniable priority over cadaver procurement for the medical schools. It is demonstrated that transplant donors are on average at least 20-30 years younger than typical whole-body donors and the general public is 
unaware of this fact, which has played an additional role in low response to body donations in many countries. It is therefore important to understand that such a misapprehension should be considered as an important factor in the publicity campaign for whole body donation for anatomy education and research in medical sciences[37].

\section{FUTURE STRATEGIES-STEPS FOR BREAKING POOR AVAILABILITY OF CADAVER}

Form the foregoing reports, it has now been established that challenges of shortage of cadaver supply can only be solved with voluntary whole body donation campaigns, focusing solely not on altruistic motives, but must include the aspect of possible personal achievement by the donor. This may be fruitful starting point for approaching potential donors giving consideration to anticipating their needs such as "their wish to be useful after death". There are some surveys suggest that body donation is more than an altruistic act; people are motivated by personal benefit, meaningful social recognition, and appreciation of their generous valuable contribution to human mankind, respectful behavior and commemorative esteemed to upheld donor's supportive social network and meaningful relationships after death. It is seen that tradition of holding memorial burial and committal services such as instituting award to donor at the time of receipt of dead body, as an appreciation of the generous and valuable body donations, have motivated the others of his social network to voluntary donation, thereby increasing availability of cadavers for dissection \& research. It may be emphasized that voluntary donation programme for the education and research purpose has very poor relevance to social acceptance of provisions of Anatomy Acts, instead there is a need to embark on a more aggressive enlightenment campaign to the society with solutions addressing the age, sex, religious faith, racial or ethical values, socio-economic factors, attitude of dependents, marital status, and attitudes about religion/spirituality, trust in hospitals, and personal achievement of donors and their relatives. It has been reported that ceremonies involving family members of voluntary donor for paying respect and tribute to generosity exhibited by body donors not only cleanse the bereavement and sorrow of donor's family but also make them feel proud to have earned the appreciation and veneration that they deserve[38,39]. It is also emphasized that medical students must taught to understand that the significance of cadaver dissection is not merely a process of learning anatomy but significance of priceless donor's life associated with emotional, religious social and physical values and their redressal by professional aptitude. Such practices have been demonstrated to reverse the family member's strong opposition toward body donation[40].

The body donation program has been recognized as a principal teaching tool for the teaching gross anatomy worldwide. The literature survey has also demonstrated that structured step-wised campaign to encourage willed body donation in some of the countries such as Korea, Netherlands, America and some medical colleges of India has been able to solve the shortage the cadaver supply partially or as a whole. The difference in structure and steps, related to legal provisions, of voluntary body donation are likely determinants of the success of body donation program. It is therefore suggested that health sciences institutions especially the professionals form anatomy may lead the body donation program procedure as a part of their role as teachers along with medical students to present role model to common people of society. The willed body donation program may be started by (1) analysis of personality \& aptitude of voluntary body donor using a structured questionnaire to assess the motives and attitude of donors without any prejudice which should be followed by (2) analysis of knowledge, aptitude, social \& religious approach, socioeconomic values and personal achievement of donor's family as an step to frame educational objectives for general community including health professionals. The next step of the willed program is (3) registration of voluntary donors to offer an oath to donate his or her body on the basis of highest analytical score favoring the body donation on accounts of believers in religious limitations, improvements in the quality of life, their belief that the soul is separate from the body, holding appreciation ceremonies and to extend to help the global advancement of public health using their bodies for dissection and research. Importantly

It is mandatory to maintain numerous records of voluntary donation such as a death certificate, a family member's consent form, a resident identification, and additional documents that affirm the relationship between the deceased and the family members. It is worth considering the observation of some of the studies highlighted in the present paper suggesting that there are certain factors recognized key determinants in promoting voluntary donation for cadaveric dissection and research. Most important of them are (1) receive of the donated bodies with appreciation ceremonies such as offering prayer according to the belief of donor's religion, instituting award to next kin or relative of donor, moment of silence to pay tribute to donor's soul etc (2) accountability, expression \& attitude of ethical behavior of medical students and research while handling the donated bodies (3) residing place of remains of the cadaver that the family members can visit according to their wish or on their mortal day. It is the experience of the some of the universities and medical school that comprehensive frame work of structured voluntary donation programme, as detailed above, is expected to establish reliable relationship between donors and the schools of medicine to, waving off any doubt of malpractice or unethical conduct. Therefore it is essential to closely observe the motives, expectations and wishes of the potential donors. Further a strong with well defined legislation having aim of voluntary donation, validity of will and informed consent for whole body donation, personal data confidentiality, designation of anatomical procedures, procedure for the remains and 
commemorative services will provide strong teeth to the willed programme for whole-body donation, a sustainable solution to the deficient cadaver supply to the medical \& health education and research.

\section{SUMMARY}

Requirement of human cadavers and human material has been the used since long to provide foundation of medical sciences to the medical students and to provide the answers to the terminal underlying illnesses for development of treatment. Growing medical sectors and health sciences experts desires to have great deal of information for many ill-defined diseases. Hence in order to provide a sustainable solution to the requirement of health professionals for human material to conduct experiments and learning anatomy it is desirable to develop and efficiently promote voluntary body donation programs in structured way to ensure adequate education of health professionals and community at large laying emphasis on human ethics and appreciation to donor and its family to the contribution to social and human well being.

\section{REFERENCES}

[1] Davidson M. (1995) The New Physician, 44::30-35

[2] Lagwinski M., Bernard J.C., Keyser M.L., Dluzen D.E. (1998) Clin Anat., 11:253-2.

[3] Jefferies D.E. (1998) Ind J Global Legal Stud, 5:621-58.

[4] Jones D.G., Gear R., Galvin K.A. (2003) J Med Ethics,29:343-7.

[5] Patnaik V.V.G. (2002) J Anat Soc India,50(2): 143-4.

[6] Coelho D.H., Caplan A.L.( 1997) Acad Med ,72:741-743.,

[7] Labuschagne B.C., Mathey B. (2000) Clin Anat 13:88-93.

[8] Gangata H., Ntaba P., Akol P., Louw G. (2010) Anat Sci Educ 3:174-183.

[9] Osuagwu F., Imosemi I., Oladejo O. (2004) Afr J Biomed Res 7:93-95.

[10] Chakraborty S., Khan H., Islam S., Yousuf B. (2010) Bangladesh J Anat 8:85-88.

[11] de Melo E.N., Pinheiro J.T. (2010) Rev bras educ med 34:315-323.

[12] Ajita R., Singh Y.I. (2007) J Anat Soc India 56:44-47.

[13] Dasgupta N. (2004) JAMA 291:122.

[14] FunkT., URL: http://www.charlotteobserver.com/2010/08/ 22/1636629/more-bodies-are-goingunclaimed.html [accessedMarch 2011].

[15] Harrington D.E., Sayre E.A. (2010) Regulation Winter:14-19.

[16] Koranda J. (2010) The Wichita Eagle, June 27. URL: http://www.kansas.com/2010/06/27/ 1379506/state-ends-funds-for-funerals.html [accessed March 2011].
[17] Saker A., The Oregonian, June 14. URL: http:// www.oregonlive.com/ special/ index.ssf/2009/06/disposition_of_unclaimed_b odie.html [accessed March 2011].

[18] Jones D.G., Gear R., Galvin K.A. (2003) J Med Ethics;29:343-7.

[19] Groscurth P., Eggli P., Kapfhammer J., Rager G., Hornung J.P., Fasel J.D. (2001) Anat Rec, 265:254-6.

[20] Gunderman R.B. (2008) Anat Sci Educ 1:217219.

[21] Boulware L.E., Ratner L.E., Cooper L.A., LaVeist T.A., Powe N.R. (2004) Clin Anat ,17:570-7.

[22] Lagwinski M., Bernard J.C., Keyser M.L., Dluzen D.E. (1998) Clin Anat 11:253-2.

[23] Jones D.G., Whitaker M.I. (2009) Clin Anat 22:770-776.

[24] Ballala K., Shetty A., Malpe S.B. (2011) Anat Sci Educ. ,4(3):142-50.

[25] Jones D.G., Fennell S.Bequests(2011) N Z Med J., 104:210-212

[26] Bolt S., Eisinga R., Venbrux E., Kuks J.B., Gerrits P.O. (2011) Ann Anat.,193(2):1127.

[27] Chung C.S. Lehman L.S. (2002) Arch Pathol Lab Med, 126(8): 964-8.

[28] Boulware L.E., Ratner L.E., Sosa J.A., Cooper L.A., Laveist T.A., Powe N.R. (2002) Transplantation , 73(10): 1683-91.

[29] Golchet G. Carr J. Harris M.G. (2008) Optometry, 71(5): 318-28.

[30] Bolt S., Venbrux E., Eisinga R., Gerrits P.O. (2011) Clin Anat., 193(3),67-70.

[31] Bolt S., Eisinga R., Venbrux E., Kuks J.B., Gerrits P.O. (2010) Ann Anat. Apr 20,192(2):70-4.

[32] Nnodim J.O., Ohnaka E.C. and Osuji C.U. (1996) Clin. A nat., 9: 258-262.

[33] Jones, L.S., Paulman L.E., Thadani R. and Terracio L. (2001) Med. Educ. Online, 6, 2.

[34] Yeager V.L. (1981) J.Med. Educ., 56: 922.

[35] Barrows H.S. and Tamblyn R.M. (1980) Problem-Based Learning: an Approach to Medical Education. Springer, New York.

[36] Cantarovich F. (2005) Ann Transplant, 10(1): 22-5.

[37] Azis, M.A., Mckenzie J.C., Wilson J.S., Cowie R.J., Ayeni S.A. and Dunn B.K. (2002) Anat. Rec., 269(1): 20-32.

[38] Lee S.M.(2004) J Sokdang Acad Res Tradit Cult 34:127-180.

[39] Tanner L.,Pantagraph.com, Bloomington I.L. URL: $\quad$ http://www.pantagraph.com/ news/national/article_1dd94f9e-bf48-11df87f5-001cc4c00 2e0. html [accessed 20 November 2010].

[40] Gunderman R.B. (2008) Anat Sci Educ 1:217-219. 